\title{
Corticosteroid Therapy for Brain Tumor Patients with Adrenal Insufficiency
}

\author{
Irwan Barlian Immadoel $\mathrm{Haq}^{1}$, Dirga Rachmad Aprianto ${ }^{2}$, Rahadian Indarto Susilo ${ }^{1}$, Joni Wahyuhadi ${ }^{1 *}$ \\ ${ }^{1}$ Department of Neurosurgery, Faculty of Medicine, Airlangga University, Dr. Soetomo Academic General Hospital, Surabaya, \\ Indonesia; ${ }^{2}$ Departement of Surgery, Medical College, Universitas Islam Sultan Agung, Semarang, Indonesia
}

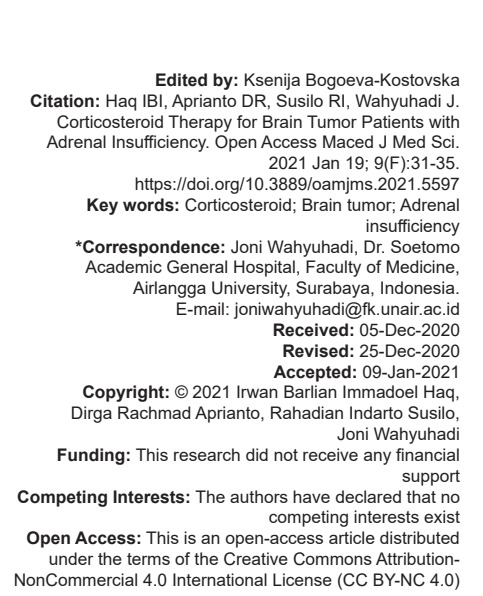

\section{Introduction}

The use of corticosteroids in cases of brain tumors has become common. In brain tumors, corticosteroid is primarily intended to reduce the tumor-surrounding edema, thus lessening the mass effect to the brain. Further, due to its glucocorticoid activity, corticosteroid can also be used to target lymphoma in the central nervous system, and also to prevent or treat chemotherapy-induced nausea and vomiting [1].

Although corticosteroid is widely used, however, there is a serious concern in the effect of steroid. Prolonged use with large dose and inappropriate withdrawal of corticosteroid tends to cause adrenal insufficiency $(\mathrm{Al})$, which might cause morbidity and mortality to patients [2]. Al can also occur in cases of pituitary macroadenoma that has undergone surgery [3], [4]. The presence of Al, therefore, will affect the treatment of brain tumor patients [4]. This paper will discuss about corticosteroid management in brain tumor patients with $\mathrm{Al}$.

\section{Physiology of Cortisol in Brain Surgery}

Corticotrophin-releasing hormone (CRH), released by the hypothalamus, stimulates the anterior pituitary to secrete adrenocorticotropic hormone (ACTH) into the bloodstream. To complete the hypothalamicpituitary (HPA) axis, cortisol (the stress hormone) is then produced by adrenal glands following ACTH stimulation. The HPA axis is regulated by a negative feedback mechanism in which cortisol suppresses the release of both $\mathrm{CRH}$ and $\mathrm{ACTH}$. Cortisol is a catabolic glucocorticoid hormone that mobilizes energy stores to prepare the body for the fight or flight response to stressors. It promotes gluconeogenesis in the liver, leading to raised blood glucose levels. Hyperglycemia, however, reduces the rate of wound healing and is associated with an increase in infections and other comorbidities including ischemia, sepsis, and death [5]. Aside from its metabolic effect, cortisol is also a potent anti-inflammatory hormone capable of preventing the widespread tissues and nerve damage associated with inflammation [6]. Moreover, cortisol is also reported 
to have an effect on the cardiovascular system, due to the contribution of endogenous cortisol secretion on the circadian rhythm of blood pressure [7], [8]. Dysregulation on HPA has also been suggested as one of the factors involved in the pathogenesis of essential hypertension [9], [10]. Exogenous corticosteroids are also known to have an effect on increased risk of cardiovascular and cerebrovascular diseases [11]. On the other hand, lack of cortisol, such as in Al, also has its own consequences. The most dangerous complication of $\mathrm{Al}$ is adrenal crisis, which can lead to death mostly due to hypoglycemic shock [12], [13].

Following surgical or accidental trauma, the nervous system activates the stress response by sending impulses from the injured site to the hypothalamus. The hypothalamus either removes its inhibitory tone on the pituitary or releases hormones which stimulate the production and/or release of pituitary hormones. Pituitary hormones act on their respective target organ causing the release of hormones such as the stress hormone and cortisol [14].

During and after surgery high levels of both ACTH and cortisol persist in the blood. Beside the grade of surgery, high cortisol level is also affected by anesthesia. The type of anesthesia also determines the effect on cortisol level, in which general anesthesia raises higher cortisol level right after the administration and returns back to normal level at after 24-48 h after uncomplicated surgery [15]. The time in which a surgery is performed also appears to have an effect on the cortisol level in a day. Cortisol level on surgery during later periods (i.e., afternoon) in a day is reported to result in earlier return to normal level compared to earlier periods (i.e., morning) [16]. In the presence of raised cortisol levels in a severe stress response, the rate of protein breakdown exceeds that of protein synthesis, resulting in the net catabolism of muscle proteins to provide substrates for gluconeogenesis. Further substrates for gluconeogenesis are provided through the breakdown of fat. Triglycerides are catabolized into fatty acids and glycerol, a gluconeogenic substrate [5], [14].

\section{Al in Brain Tumor}

$\mathrm{Al}$ is a serious concern in brain tumor patients. Almost all patients with brain tumors receive corticosteroids at some point in the course of their disease [17], [18]. The use of corticosteroids in brain tumor patients can cause Al if used in long-term with large doses and with rapid withdrawal, thus causing suppression of the HPA [2]. In prolonged suppression of HPA, adrenal glands eventually atrophy and take months to years to recover some degree of functioning [19]. The incidence of $\mathrm{Al}$ in cases of corticosteroid use in cases of brain tumors ranged from $1 \%$ to $2 \%$ [2].
Al in brain tumors can also be found in cases of pituitary macroadenoma that has undergone excision surgery. Manipulation and damage to the pituitary gland during surgery may prevent the proper secretion of ACTH, disrupting the HPA axis and secretion of the cortisol [20]. The incidence of $\mathrm{Al}$ in post-operative macroadenoma cases is about 5-10\% [3], [21]. Pituitary hemorrhage or infarction (Sheehan syndrome) can also lead to secondary Al [12].

\section{Management of Secondary Al in Brain Tumor Patients Whom Receives Long- term Corticosteroids}

Determination of $\mathrm{Al}$ after long-term corticosteroid administration in brain tumor patients is carried out the same way as in other patients. Patients at high risk are patients with a prednisone dose of $\geq 20$ $\mathrm{mg} /$ day, or equivalent treatment for more than 3 weeks, or; dose $\geq 5 \mathrm{mg}$ of prednisone administered during the evening/night for more than 2 weeks, or; patients with clinical signs of Cushing syndrome [22].

Tests performed include the insulin hypoglycemia test, short stimulation test with synthetic ACTH at standard dose, short stimulation test with synthetic ACTH at low dose, metyrapone test, and glucagon test [23], [24], [25], [26], [27]. The determination of $\mathrm{Al}$ should be carried out in a multidisciplinary manner with an endocrinologist as the main determinant [4], [22].

Once established, $\mathrm{Al}$ must be managed immediately to prevent adrenal crisis. The management of secondary $\mathrm{Al}$ in brain tumor cases is based on glucocorticoid replacement. In secondary $\mathrm{Al}$, mineralocorticoid production is preserved because aldosterone secretion is mainly regulated by the reninangiotensin system with minimal dependence on $\mathrm{ACTH}$; therefore, do not require mineralocorticoid replacement therapy [22].

Hydrocortisone is currently recommended as the glucocorticoid of choice in case of Al. The use of hydrocortisone allows for reaching optimum cortisol levels $30 \mathrm{~min}$ after oral intake [28]. Hydrocortisone has a mean plasma half-life of $95 \mathrm{~min}$. Its high oral bioavailability and short half-life result in a profile with high peaks 1-2 $\mathrm{h}$ after administration, followed by a rapid decline after 5-7 $\mathrm{h}$ [29].

Although the current rapid release presentations of hydrocortisone are not able to mimic circadian rhythm of cortisol, an attempt is made to approximate this by giving divided doses. To avoid glucocorticoid overexposure, especially from midafternoon (because of its relationship to insulin resistance and the untoward metabolic consequences), various schemes have been 
proposed. Recommended doses are $15-20 \mathrm{mg}$ or 30 $\mathrm{mg}$ of oral hydrocortisone daily. Options of dividing the dosage include dividing the dose into two fractions (2/3 of the total dose in the morning upon awakening and $1 / 3$ in midafternoon) or three fractions (1/2 of the total dose at $7 \mathrm{AM}, 1 / 4$ at $12 \mathrm{AM}$, and $1 / 4 \mathrm{mg}$ at 4:30 PM) by avoiding administration later than 6 PM [4], [22]. Although there is no convincing evidence, three divided doses may partly correct the afternoon nadir in cortisol levels which occurs if two doses are administered [30], [31].

Monitoring of long-term glucocorticoid treatment in brain tumor patients is essential. The dose of glucocorticoid, if necessary, can be modified based on clinical symptoms and signs [29]. There are no objective parameters to assess the quality of replacement therapy. The lowest dose of glucocorticoid, based on weight calculation that relieves symptoms of glucocorticoid deficiency should be used to prevent overdosing [32], [33]. It is important to estimate daily dose of glucocorticoid and its distribution, and to adjust treatment to stress and intercurrent diseases [29].

The main clinical assessments for Al patients are weight control (measured and recorded periodically), clinical signs of Al, and signs of hypercortisolism/ Cushing syndrome. Routine measurement of ACTH or cortisol curves is not required [22]. If patients have symptoms of glucocorticoid deficiency (fatigue, lack of energy, nausea, myalgia, and weight loss), dosage should be increased. However, if symptoms do not improve, treatment should be resumed at the previous dose and other potentially responsible causes should be assessed [32]. Dose will be excessive if symptoms or signs of Cushing syndrome occur (weight increase, central obesity, striae, osteoporosis, insomnia, edema, HBP, and impaired glucose metabolism) [22].

\section{Management of Secondary Al in Brain Tumor Patients Whom Undergo Brain Surgery}

Insufficient cortisol production during a surgical stress response leads to adrenal crisis. This condition is marked by progressive loss of vasomotor tone and impaired alpha-adrenergic receptor responses to noradrenaline. Ongoing reductions in vascular tone lead to orthostatic hypotension followed by supine hypotension and finally shock, which will be fatal if not rapidly corrected. A tendency on water retention and hyponatremia induced by antidiuretic hormone is very common after surgery. Thus, patients with insufficient aldosterone production will be particularly susceptible to hyponatremia [34].

Surgical stress is not an all or nothing phenomenon. The level of surgical stress is varied for each patient. Patient-specific, surgical, and anesthetic procedures are factors that determine the level of surgical stress, as well as its pre-operative and post-operative care. In a recent systematic review and meta-analysis by Prete et al., perioperative cortisol concentrations in 2953 patients were escalated and more prominent in older subjects and woman with procedures involving open surgery and general anesthesia [35].

The recommendations of hydrocortisone adjusting dosage for brain tumor patients whom undergo brain surgeryare divided into pre-operative, intraoperative, and post-operative adjustment. The recommendation of pre-operative adjustment is the administration of 100 mg of hydrocortisone intravenously right before the anesthesia followed by continuous infusion of $200 \mathrm{mg}$ of hydrocortisone in $24 \mathrm{~h}$. For post-operative treatment, continuous infusion of $200 \mathrm{mg}$ of hydrocortisone in $24 \mathrm{~h}$ or $50 \mathrm{mg}$ of hydrocortisone intramuscularly per $6 \mathrm{~h}$ can be given if enteral administration is not possible. If enteral administration is possible, hydrocortisone dose can be doubled for $48 \mathrm{~h}$ before continue with usual treatment dose. In patients whom receive hydrocortisone treatment for more than 4 weeks before surgery, double dose of hydrocortisone can be given for $48 \mathrm{~h}$ up to 1 week after surgery followed with usual treatment dose [34].

\section{Management of Al in Pituitary Adenomas Patient Whom Undergo Tumor Removal Surgery}

Management of $\mathrm{Al}$ in pituitary adenomas patient is different and more complex, especially for post-operative requirements. The pre-operative and intraoperative requirements are nearly same as other brain tumor patients with $\mathrm{Al}$ whom undergo brain surgery. Another strategy is by giving hydrocortisone sodium succinate can be given $50 \mathrm{mg}$ intramuscularly at $11 \mathrm{PM}$ and $6 \mathrm{AM}$ (before surgery) and right before surgery $50 \mathrm{mg}$ of hydrocortisone mixed with $1000 \mathrm{ml}$ of D5LR $+20 \mathrm{mEq} \mathrm{KCl} / \mathrm{l}$ are given at the rate of $75 \mathrm{ml} / \mathrm{h}$. During surgery, intravenous administration of $100 \mathrm{mg}$ of hydrocortisone can be given every $8 \mathrm{~h} \mathrm{[4].}$

Post-operative management of steroid is trickier in these patients. For the patients with adequate level of cortisol before surgery and low suspicious of ACTH deficiency after surgery, the $50 \mathrm{mg}$ of hydrocortisone can be given intramuscularly or by intravenous infusion every 6 h for 24 h after surgery. On day 2 after surgery, the steroid regiment is then changed to enteral prednisone with the dose of $5 \mathrm{mg}$ every $6 \mathrm{~h}$, followed by $5 \mathrm{mg}$ of prednisone every $12 \mathrm{~h}$. The steroids can be discontinued after 5 days [4].

However, if there is hypocortisolemic condition before surgery or there is a suspicious of possibility 
of ACTH deficiency in the patient after surgery, the approach is very different. The $50 \mathrm{mg}$ of hydrocortisone can be given intramuscularly or by intravenous infusion every 6-12 h and taper and stopped after 24-48 h postoperatively. After $24 \mathrm{~h}$ of discontinuation, check the $6 \mathrm{AM}$ cortisol level. If the cortisol level is $>9 \mathrm{mcg} / \mathrm{dl}$, then no further tests or treatment required. However, if the cortisol level is lower than $9 \mathrm{mcg} / \mathrm{dl}$, there is a possibility of ACTH deficiency that is harmful to the patient. If adrenal reserve can be formally assessed, patient can be discharged on $50 \mathrm{mg}$ of hydrocortisone every AM and 25 mg every 4 PM usually until 1 month after surgery [4].

The hydrocortisone then tapered at home $10 \mathrm{mg} /$ doses daily for 2-3 weeks down to $20 \mathrm{mg}$ every AM and $10 \mathrm{mg}$ every $4 \mathrm{PM}$ and it holds for several days, usually until 1 month after surgery as mentioned above. The patient was then asked to hold the PM dose and check an 8 AM serum cortisol the next day before taking the AM dosage. To avoid $\mathrm{Al}$ in patients with incompetent reserve, as soon as the blood is drawn have the patient take their morning cortisol dose and resume regular dosing until the test results are available. If $8 \mathrm{AM}$ cortisol test shows any significant adrenal function (>9 mcg/dl), then taper the patient off hydrocortisone [4], [36].

The problem is when the patient's $8 \mathrm{AM}$ cortisol test is under $9 \mathrm{mcg} / \mathrm{dl}$. The guideline suggests the use of metyrapone test. This test more accurately assesses the HPA-adrenal axis and is useful if there is suspicion of reduced reserve of pituitary ACTH production. Metyrapone inhibits 11- $\beta$-hydroxylation in the adrenal cortex, reducing production of cortisol and corticosterone with concomitant increase of serum 11-deoxycortisol precursors and its 17-OHCS metabolites which appear in the urine. In response, a normal pituitary increases ACTH production. First of all, the patients should have a synthetic ACTH stimulation test first to rule out primary Al. This test is forbidden if there is known primary $\mathrm{Al}$ and the patient must be tested as an inpatient. The patient will be given 2-3 g metyrapone at midnight. On the next morning, the serum 11-deoxycortisol level will be checked. Normal response is a 11-deoxycortisol level $>7 \mathrm{mcg} / \mathrm{dl}$. If the level is below $7 \mathrm{mcg} / \mathrm{gl}$, the ACTH deficiency can be ruled in and the permanent hydrocortisone treatment, as in other Al patients must be given [4].

\section{Summary}

$\mathrm{Al}$ is one of serious and problematic concern in brain tumor patients who receive steroid therapy or after pituitary macroadenoma surgery. Improper steroid management in these patients can lead to morbidity and even mortality. Therefore, exact diagnosis and appropriate steroid therapy in brain tumor patients with $\mathrm{Al}$ is essential, particularly those who undergo surgery.
Dosage of steroid can be adjusted depends on surgical stress and patient's condition after surgery in collaboration with anesthesiologist and endocrinologist [1].

\section{Acknowledgment}

The completion of this paper could not have been possible without the support and assistance of seniors of the Faculty of Medicine, Universitas Airlangga and many others whose names cannot be mentioned one by one.

\section{References}

1. Roth $\mathrm{P}$, Happold $\mathrm{C}$, Weller $\mathrm{M}$. Corticosteroid use in neurooncology: An update. Neurooncol Pract. 2015;2(1):6-12. https:// doi.org/10.1093/nop/npu029

PMid:26034636

2. Da Silva AN, Schiff D. Adrenal insufficiency secondary to glucocorticoid withdrawal in patients with brain tumor. Surg Neurol. 2007;67(5):508-10. https://doi.org/10.1016/j. surneu.2006.07.018

PMid:17445619

3. Burgers AM, Kokshoorn NE, Pereira AM, Roelfsema F, Smit JW, Biermasz NR, et al. Low incidence of adrenal insufficiency after transsphenoidal surgery in patients with acromegaly: A long-term follow-up study. J Clin Endocrinol Metab. 2011;96(7):1163-70. https://doi.org/10.1210/endo-meetings.2011.part3.p30.p3-284 PMid:21470989

4. Greenberg MS. Handbook of Neurosurgery. $9^{\text {th }}$ ed. New York: Thieme Medical Publishers, Inc.; 2020.

5. Gore DC, Jahoor F, Wolfe RR, Herndon DN. Acute response of human muscle protein to catabolic hormones. Ann Surg. 1993;218(5):679-84. https://doi. org/10.1097/00000658-199311000-00015 PMid:8239784

6. Heim C, Ehlert U, Hellhammer DH. The potential role of hypocortisolism in the pathophysiology of stress-related bodily disorders. Psychoneuroendocrinology. 2000;25(1):1-35. https:// doi.org/10.1016/s0306-4530(99)00035-9

PMid:10633533

7. Imai $Y$, Abe K, Sasaki S, Minami N, Nihei M, Munakata M, et al. Altered circadian blood pressure rhythm in patients with cushing's syndrome. Hypertension. 1988;12(11):11-9. https:// doi.org/10.1161/01.hyp.12.1.11

PMid:3397172

8. Giraldi F, Toja P, De Martin M, Maronati A, Scacchi M, Omboni S, et al. Circadian blood pressure profile in patients with active Cushing's disease and after long-term cure. Horm Metab Res. 2007;39(12):908-14. https://doi.org/10.1055/s-2007-992813 PMid:18046661

9. Walker BR, Stewart PM, Shackleton $\mathrm{CH}$, Padfield PL Edwards CR. Deficient inactivation of cortisol by 11 betahydroxysteroid dehydrogenase in essential hypertension. Clin Endocrinol (Oxf). 1993;39(2):221-7. https://doi. org/10.1111/j.1365-2265.1993.tb01778.x 
PMid:8370136

10. Watt G, Harrap S, Foy C, Holton D, Edwards H, Davidson R, et al. Abnormalities of glucocorticoid metabolism and the renin-angiotensin system: A four-corners approach to the identification of genetic determinants of blood pressure. J Hypertens. 1992;10(5):473-82. https://doi. org/10.1097/00004872-199205000-00011

PMid:1350793

11. Souverein PC, Berard A, Van Staa TP, Cooper C, Egberts AC, Leufkens HG, et al. Use of oral glucocorticoids and risk of cardiovascular and cerebrovascular disease in a population based case-control study. Heart. 2004;90(8):859-65. https://doi. org/10.1136/hrt.2003.020180

PMid:15253953

12. Huecker M, Dominique E. Adrenal Insuffiency. Treasure Island, FL: StatPearls; 2020.

13. Fischer JE, Stallmach T, Fanconi S. Adrenal crisis presenting as hypoglycemic coma. Intensive Care Med. 2000;26(1):105-8. https://doi.org/10.1007/s001340050021

PMid:10663290

14. Finnerty CC, Mabvuure NT, Ali A, Kozar RA, Herndon DN. The surgically induced stress response. J Parenter Enteral Nutr. 2013;37(5):21S-9. https://doi.org/10.1177/0148607113496117 PMid:24009246

15. Ntonas G, Eleftheriadis S, Chatziioakeimidis C, Christofis C, Vogiatzaki T, Chloropoulou P, et al. Cortisol and perioperative period. Could be certified any correlation? Khirurgiia (Sofiia). 2014;3:28-36. PMid:25799621

16. Kwon YS, Jang JS, Hwang SM, Tark H, Kim JH, Lee JJ, etal. Effects of surgery start time on postoperative cortisol, inflammatory cytokines, and postoperative hospital day in hip surgery: Randomized controlled trial. Medicine (Baltimore). 2019;98(24):e15820. https:// doi.org/10.1097/md.0000000000015820

PMid:31192911

17. Osoba D. Health-related quality of life and cancer clinical trials. Ther Adv Med Oncol. 2011;3(2):57-71. https://doi. org/10.1177/1758834010395342

PMid:21789156

18. Schiff D, Lee EQ, Nayak L, Norden AD, Reardon DA, Wen PY. Medical management of brain tumors and the sequelae of treatment. Neuro Oncol. 2015;17(4):488-504. https://doi. org/10.1093/neuonc/nou304

PMid:25358508

19. Currie H, Ali M. Dexamethasone-related adrenal insufficiency in patients with solid brain tumours. Endocr Abstr. 2014;34:450. https://doi.org/10.1530/endoabs.34.p354

20. Stamper T, Goldenberg N, Sharma S. Adrenal insufficiency after pituitary surgery: Basic level. Mayfield Clinic. 2010;1:1-2.

21. Fatemi N, Dusick JR, Mattozo C, McArthur DL, Cohan P, Boscardin J, et al. Pituitary hormonal loss and recovery after transsphenoidal adenoma removal. Neurosurgery. 2008;63(4):709-18. neu.0000325725.77132.90

PMid:18981881

22. de Miguel Novoa P, Vela ET, Garcia NP, Rodriguez MM, Guerras IS, de Los Ángeles Martínez de Salinas Santamaría M, et al. Guidelines for diagnosis and treatment of adrenal insufficiency in adults. Endocrinol Nutr. 2016;61(1):1-34. https:// doi.org/10.1016/s2173-5093(14)70069-8

PMid:25128212

23. Reimondo G, Bovio S, Allasino B, Terzolo M, Angeli A. Secondary hypoadrenalism. Pituitary. 2008;11(2):147-54. https://doi.org/10.1007/s11102-008-0108-4

PMid:18418713
24. Dorin RI, Qualls CR, Crapo LM. Diagnosis of adrenal insufficiency. Acad Clin. 2003;139(4):194-204. https://doi. org/10.7326/0003-4819-139-3-200308050-00009

25. Ferrante E, Morelli V, Giavoli C, Mantovani G, Verrua E, Sala E, et al. Is the $250 \mu \mathrm{g} \mathrm{ACTH}$ test a useful tool for the diagnosis of central hypoadrenalism in adult patients with pituitary disorders? Hormones. 2012;11(4):428-35. https://doi.org/10.14310/horm.2002.1374 PMid:23422765

26. Suliman AM, Smith TP, Labib M, Fiad TM, McKenna TJ. The low-dose ACTH test does not provide a useful assessment of the hypothalamic-pituitary-adrenal axis in secondary adrenal insufficiency. Clin Endocrinol (Oxf). 2002;56(4):533-9. https:// doi.org/10.1046/j.1365-2265.2002.01509.x

PMid:11966747

27. Karaca Z, Lale A, Tanriverdi F, Kula M, Unluhizarci K, Kelestimur F. The comparison of low and standard dose ACTH and glucagon stimulation tests in the evaluation of hypothalamopituitary-adrenal axis in healthy adults. Pituitary. 2011;14(2):13440. https://doi.org/10.1007/s11102-010-0270-3

PMid:21061072

28. Falorni A, Minarelli $\mathrm{V}$, Morelli S. Therapy of adrenal insufficiency: An update. Endocrine. 2013;43(3):514-28. https://doi. org/10.1007/s12020-012-9835-4 PMid:23179775

29. Grossman A, Johannsson G, Quinkler M, Zelissen P. Therapy of endocrine disease: Perspectives on the management of adrenal insufficiency: Clinical insights from across Europe. Eur J Endocrinol. 2013;169(6):165-76. https://doi.org/10.1530/ eje-13-0450

PMid:24031090

30. Quinkler M, Hahner S. What is the best long-term management strategy for patients with primary adrenal insufficiency? Clin Endocrinol (Oxf). 2012;76(1):21-5. https://doi. org/10.1111/j.1365-2265.2011.04103.x

PMid:21585418

31. Reisch $N$, Arlt W. Fine tuning for quality of life: $21^{\text {st }}$ century approach to treatment of addison's disease. Endocrinol Metab Clin North Am. 2009;38(2):407-18. https://doi.org/10.1016/j. ecl.2009.01.008

PMid:19328419

32. Nieman L. Treatment of Adrenal Insufficiency in Adults. United States: UpToDate; 2013.

33. Mah PM, Jenkins RC, Rostami-Hodjegan A, Newell-Price J, Doane A, Ibbotson $\mathrm{V}$, et al. Weight-related dosing, timing and monitoring hydrocortisone replacement therapy in patients with adrenal insufficiency. Clin Endocrinol (Oxf). 2004;61(3):367-75. https://doi.org/10.1111/j.1365-2265.2004.02106.x

PMid:15355454

34. Woodcock T, Barker $P$, Daniel $S$, Fletcher $S$, Wass JA, Tomlinson JW, et al. Guidelines for the management of glucocorticoids during the peri-operative period for patients with adrenal insufficiency: Guidelines from the association of anaesthetists, the royal college of physicians and the society for endocrinology UK. Anaesthesia. 2020;75(5):654-63. https://doi. org/10.1111/anae.14963

PMid:32017012

35. Prete A, Yan Q, Al-Tarrah K, Akturk HK, Prokop LJ, Alahdab F, et al. The cortisol stress response induced by surgery: A systematic review and meta-analysis. Clin Endocrinol. 2018;89(5):554-67. https://doi.org/10.1111/cen.13820 PMid:30047158

36. Watts NB, Tindall GT. Rapid assessment of corticotropin reserve after pituitary surgery. JAMA. 1988;259(5):708-12. https://doi. org/10.1001/jama.1988.03720050044021

PMid:2826832 